\title{
O PAPEL DAS COMUNIDADES PARA CONSTRUÇÃO DE CIDADES RESILIENTES: O CASO DO JARDIM DE CHUVA DO LARGO DAS ARAUCÁRIAS, PINHEIROS (SP)
}

Elis Cristina Morales dos Santos

\section{RESUMO}

Atualmente a maioria dos grandes centros urbanos, a exemplo da cidade de São Paulo, têm enfrentado desafios como enchentes recorrentes, aumento das ilhas de calor, contaminação do solo, desigualdade social, dentre outros, os quais resultam da somatória da história local aos crescentes efeitos das Mudanças Climáticas, fazendo com que cidades e seus habitantes experienciem seus limites físicos e anímicos, colocando à prova suas capacidades de resiliência. Frente a esta realidade, nascem novas formas de se pensar e construir as cidades, como o conceito de biofilia, e também de reivindicação, com crescente participação dos moradores, os quais respondem aos desafios através de intervenções urbanísticas que transformam significativamente a paisagem e a dinâmica local. Assim, este artigo tem como objetivo analisar o papel de intervenções paisagísticas originárias de coletivos e comunidades locais para construção de cidades resilientes. E ao trazer uma análise do Largo das Araucárias, faz ainda um paralelo com o conceito de cidades biofílicas.

\section{Palavras-chave}

Cidades Resilientes. Cidades Biofílicas. Comunidades. Jardim de Chuva. Largo das Araucárias. 


\title{
THE COMMUNITY ROLE FOR THE CONSTRUCTION OF RESILIENT \\ CITIES: THE CASE OF THE RAIN GARDEN IN THE LARGO DAS ARAUCÁRIAS, PINHEIROS-SP
}

Elis Cristina Morales dos Santos

\begin{abstract}
Currently, most large urban centers, such as the city of São Paulo, have faced challenges such as recurrent floods, increased heat islands, soil contamination, social inequality, among others, which result from the sum of local history to the growing effects of Climate Change, making cities and their inhabitants experience their physical and soul limits, testing their resilience capabilities. Facing this reality, new ways of thinking and building cities are born, such as the concept of biophilia, and also demand, with increasing participation of residents, who respond to challenges through urban interventions that significantly transform the landscape and local dynamics. Thus, this article aims to analyze the role of landscape interventions originating from collectives and local communities for the construction of resilient cities. And by bringing an analysis of Largo das Araucárias, it also makes a parallel with the concept of biophilic cities.
\end{abstract}

\section{Keywords}

Resilient Cities. Biophilic Cities. Communities, Rain Garden. Largo das Araucárias. 


\section{INTRODUÇÃO}

Os seres humanos tendem a mimetizar a Natureza, seja em suas condições físicas, químicas ou biológicas, como conceitualizada através da biomimética, área que estuda estratégias e princípios criativos da natureza com objetivo de obter soluções para os problemas da humanidade através da estética, funcionalidade e sustentabilidade. E isso não se difere quando se trata em analisar, estudar e compreender o planejamento e construção das cidades.

Entretanto, mesmo que essa apropriação seja cada vez mais recorrente e que termos como "cidades sustentáveis" e "cidades resilientes" apareçam frequentemente nas discussões atuais na esfera acadêmica ou fora dela, a relação de distanciamento entre seres humanos e natureza vem se agravando desde a revolução industrial, levando cada vez mais a sociedade atual a encarar desafios como a da construção de cidades capazes de enfrentar grandes crises resultantes de eventos relacionados à mudanças climáticas, destruição da Natureza e aumento da desigualdade social.

As possíveis soluções para reverter este cenário são muitas, no entanto, é possível afirmar que todas irão envolver o ser humano de alguma forma. Não por este ser mais importante que qualquer outro ser vivo, mas por ter sido o responsável por grandes modificações e impactos no meio ambiente.

A biofilia ${ }^{1}$ é um conceito inicialmente apresentado pelo psicanalista alemão Erich Fromm na década de 1970 e que traz consigo a ideia de que os seres humanos possuem uma necessidade inata de estar em contato com a Natureza, uma vez que ela foi por muitos anos seu habitat ao invés das cidades. É a partir desta percepção que nasce o conceito de cidades biofílicas.

As cidades biofílicas, portanto, são exemplo do resultado da análise das relações originais entre humanos e natureza (biofilia), e como esta pode refletir na relação entre habitantes e cidades. Sendo assim, partindo desta mesma linha de raciocínio, seria possível traçar um paralelo entre biofilia e cidades biofílicas com resiliência e cidades resilientes?

1. o termo biofilia tem origem nas palavras gregas bios (vida) e philia (amor) e significa "amor à vida".

\section{CIDADES, CIDADÃOS E RESILIÊNCIA}

Resiliência significa a capacidade de um ecossistema, população ou de uma espécie se recuperar e retomar ao desenvolvimento normal depois de sofrer uma grande perturbação. Este conceito, absorvido da física, tem sido incorporado às cidades como forma de análise, compreensão e revisão das mesmas. Segundo Farias (2017), esta migração 
para o campo das ciências sociais e políticas públicas foi motivado por ameaças globais como crises econômicas, mudanças climáticas e terrorismo internacional, com especial atenção à capacidade de resposta dos lugares e sistemas sociais.

Assim como resiliência, o termo ecossistema também tem sido utilizado como forma de comparação entre os sistemas natural e urbano, uma vez que, assim como os ecossistemas, as cidades são compostas por comunidades de organismos vivos que transformam seu meio através de suas atividades, das trocas de matéria, energia e informação, porém, diferentemente dos ecossistemas naturais sustentáveis, as cidades são altamente dependentes, exploradoras e degradantes de si (FRANCO, 2000).

É interessante notar que apesar de haver uma tendência à mimetização da Natureza em suas funções, esta ainda é vista como elemento externo aos seres humanos e ao seu habitat. Este antagonismo é reflexo da era antropocêntrica e tem como consequência a necessidade de enfrentamento de desafios ambientais que se referem, em grande medida, a um contexto de mudanças climáticas e crises sociais.

Segundo Franco (2000), pouco se tem feito em relação a mitigação dos impactos nos centros urbanos, os quais não apenas impactam a eles próprios, como também os ambientes rurais ao seu redor, uma vez que consomem de forma insustentável os serviços naturais gerados por estes e ao mesmo tempo ofertam poluentes aos rios, ar e solos.

Uma nova abordagem está surgindo, com a crescente preocupação de grandes centros urbanos a respeito de seu impacto. Tal preocupação, apesar de ancorada no conceito de desenvolvimento sustentável, ainda não tem resultados efetivos, uma vez que, como afirma Franco (2000), são poucas as metrópoles que de fato estão sendo consideradas nos aspectos ambientais.

De acordo com Corner (2006, apud BONZI, 2015) as lentes da diferença e oposição do século XIX condicionaram as abordagens mais tradicionais de paisagem e cidade. Nesta chave dicotômica, as cidades passam a se preocupar com a tecnologia dos grandes edifícios, infraestrutura de mobilidade e a renovação de sua lucratividade, gerando efeitos não desejados como congestionamento, poluição e estresse social. A paisagem, materializada em parques, corredores verdes, arborização urbana, entre outros, surgiria, por sua vez, como um contraponto a estes efeitos deletérios da urbanização. E mesmo que, ainda segundo Corner (2006, apud BONZI, 2015), a síntese entre urbanismo e paisagem não seja alcançada, o esforço empreendido nesta associação é válido uma vez que ajudará a romper com o entendimento que secciona a cidade da paisagem.

Planejamento Ambiental, segundo Bonzi (2015), é o nome que se dá a uma série de abordagens que visam conciliar o desenvolvimento de 
atividades humanas com a conservação da natureza. Dentre algumas das propostas apresentadas encontra-se o urbanismo biofílico, que traz uma nova concepção de urbanização, pensada para proporcionar aos habitantes de áreas urbanas maior contato com a natureza.

O conceito de biofilia, do qual deriva o urbanismo biofílico, se baseia na hipótese de que os seres humanos possuem a necessidade inata de estar em contato com a natureza para garantir sua saúde física e mental. Tal hipótese, formulada pelo mirmecologista Edward O. Wilson, baseiase em estudos desenvolvidos pelo psicólogo Enrich Fromm que apontam como origem desta conexão o período quando os seres humanos eram caçadores-coletores e o seu envolvimento com outros seres vivos.

Segundo Beatley (2011), há evidências de que a presença de áreas verdes nos bairros têm impactos mais amplos e difundidos do que se pode imaginar. Para demonstrar tal afirmação, o autor cita dois estudos. O primeiro, na Holanda, envolveu mais de dez mil pessoas e demonstrou uma significativa correlação entre os elementos verdes existentes nos bairros e altos níveis de saúde física e mental de seus moradores, constatando que estas pessoas reportaram menos sintomas de doenças mentais e físicas. Já o segundo estudo, ocorrido na Dinamarca em 2007, analisou a saúde de pessoas que moravam próximas de parques e áreas verdes e a importância do fácil acesso a estes locais. O resultado apontou uma maior propensão às atividades ao ar livre, assim como a locomoção através do caminhar e do andar de bicicleta, impactando diretamente, não só na saúde das pessoas, mas também na saúde das cidades.

Ambientes que proporcionam a experimentação da Natureza ajudarão a promover outros valores importantes como fortalecer os compromissos com a sustentabilidade e a viver uma vida mais saudável. Portanto, não existe outra maneira de que tenhamos uma superação da apatia ambiental dos nossos tempos atuais, tanto local quanto global, se não for garantindo que os habitantes estejam imersos na Natureza e envolvidos ativamente em sua restauração e gestão (BEATLEY, 2011).

Sob esta ótica, Beatley (2011) define cidade biofílica como:

\footnotetext{
uma cidade que coloca a natureza em primeiro lugar em seu design, planejamento e gerenciamento; reconhece a necessidade essencial do contato humano diário com a natureza, bem como os muitos valores ambientais e econômicos fornecidos pela natureza e pelos sistemas naturais. (BEATLEY, 2011, p. 45, tradução nossa) ${ }^{2}$
}

2. Cf. original "(...) it is a city that puts nature first in its design, planning, and management; it recognizes the essential need for daily human contact with nature as well as the many environmental and economic values provided by nature and natural systems"
As cidades biofílicas têm como propósito mitigar a desconexão entre pessoas e meio natural, desconexão fortemente presente em grandes centros urbanos, a exemplo da cidade de São Paulo, objeto deste trabalho. Uma possível mudança neste cenário deve ser conquistada através da população, uma vez que, como indica Beatley (2011), o nível de envolvimento ativo dos moradores, indo para além da observação 
passiva do entorno, é uma das suas características mais importante. Assim, segundo o autor, as cidades biofílicas vão além das condições físicas de seu ambiente natural, ou de um design de viés ecológico. São cidades onde o número de habitantes curiosos e envolvidos com a natureza é mais importante que a quantidade de parques e espaços verdes per capita. É necessário, portanto, priorizar programas onde moradores são incentivados a aprender sobre a natureza circundante, e não apenas quantificar os espaços urbanos verdes e arborizados.

Atualmente é visível o crescimento de iniciativas originárias da própria sociedade civil, com o objetivo de transformar os espaços urbanos em ambientes mais verdes e, consequentemente, sustentáveis e resilientes.

Trazendo esta discussão para o contexto paulistano, é possível observar pela cidade mutirões de plantios de árvores, hortas urbanas coletivas, canteiros agroflorestais, reflorestamentos, construção de jardins de chuva, bosques, telhados verdes, mobilização para abertura de parques, dentre outros. Os atores também são bastante diversificados, contando com pessoas de diferentes classes sociais, profissões, idades, gênero, que habitam nas diversas regiões da cidade e que, através das redes sociais, se organizam, mobilizam e fazem a convocação para colocar em prática aquilo que thes é de direito: uma cidade mais verde. Essa participação ativa das comunidades locais é fundamental para elaboração de métodos e abordagens do urbanismo sustentável e da resiliência urbana, mas também vêm sendo responsável pela "reconstrução" da paisagem urbana da cidade de São Paulo.

A reflexão aqui tratada ganha valioso apoio através dos ensinamentos de Besse (2014), para quem a Paisagem é um espaço social, é o meio ambiente material e vivo das sociedades e, portanto, é preciso abandonar o ponto de vista do espectador dessa sociedade e se questionar sobre o interesse dos seres humanos sobre essas paisagens.

Seguindo a mesma linha de raciocínio, Farias (2017) afirma que a herança do conceito de vulnerabilidade, formulado nos anos 1990, destaca as populações sempre como vítimas puras e incapazes de agir e de se recuperar de suas crises, resultando em uma gestão concentrada totalmente nas autoridades. Entretanto, a partir do momento que o papel da comunidade é invertido de vítima para agente através da participação, somado ao entendimento de que grupos de pessoas são capazes de enfrentar crises, o resultado é um novo modelo de responsabilidade que conduz à resiliência.

Portanto, os movimentos "bottom-up" da sociedade civil trazem consigo a condição de resiliência e, conforme Farias (2017), está mais associada à rede comunitária, à solidariedade e à aceitação do risco pelas populações, do que à morfologia da cidade com seus edifícios, suas redes e suas estruturas. 
Como visto, essa mudança de foco levanta a possibilidade de questionamento do atual modelo de desenvolvimento urbano, assim como do pensamento crítico para se construir formas mais sustentáveis e resilientes de cidades.

\section{O BAIRRO DE PINHEIROS-SP}

A cidade de São Paulo é conhecida pela sua diversidade de bairros, sendo que alguns são bastante antigos e com muita história, como o caso do bairro de Pinheiros, foco deste artigo. Localizado na região sudoeste do município, o bairro recebe este nome em virtude das espécies de Araucárias que ali existiam quando o bairro surgiu, no século $X V I$. E além de ser um dos mais antigos da cidade de São Paulo, também se caracteriza por apresentar diversas transformações espaciais a partir do século XX (MASCARENHAS, 2014). Nos próximos parágrafos será apresentado um breve histórico do bairro e suas transformações.

Surgido a partir de uma vila indígena, vale destacar dois pontos bastante conhecidos do bairro, os Largos de Pinheiros e da Batata. Locais que sempre estiveram presentes nos processos de evolução e transformação do bairro, principalmente na virada dos século XIX para XX, quando se consolidaram como pontos religiosos e de comércio popular ligado à agricultura (MASCARENHAS, 2014).

Hoje, o bairro de Pinheiros faz parte do centro expandido da cidade de São Paulo e, assim como outros bairros da capital paulista, é dividido em Alto de Pinheiros e Baixo Pinheiros, sendo este último delimitado entre a região do Largo da Batata e a Marginal Pinheiros. A região é atualmente considerada como um local estratégico pelos setores públicos e privados e por uma parcela dos moradores locais (MASCARENHAS, 2014 ). Isto se deve ao fato do bairro se caracterizar como região bem servida de infraestruturas e equipamentos, contando com estações de metrô, terminal intermodal de passageiros, grandes hospitais, universidades, bem como destinos culturais e possuir muita vitalidade urbana.

Nos últimos anos, tem-se percebido uma acelerada verticalização e alteração no padrão fundiário existente na região, com remoção do comércio popular, demolições e obras de infraestrutura. Tais mudanças têm gerado maior valorização dos espaços e imóveis e, em oposição, o surgimento de movimentos de resistências de moradores e trabalhadores de Pinheiros e do Largo da Batata, ambos contra verticalização do bairro e a favor de mais parques e de uma ocupação regular da área (MASCARENHAS, 2014).

Para Monticelli (2020), este interesse da população tem colaborado com o sentimento de pertencimento ao bairro, resultando no surgi- 
3. Operações urbanas consorciadas (OUC) são intervenções feitas sob a coordenação do Poder Público e envolvendo a iniciativa privada, empresas prestadoras de serviços públicos, moradores e usuários do local, com a finalidade de realizar transformações urbanísticas estruturais, melhorias sociais e valorização ambiental. A OUC-Faria Lima abrange os bairros de Pinheiros, Vila Olímpia e Itaim, e teve seu início com a criação da Lei $n^{\circ} 11.732 / 95$. Seu objetivo era otimizar a infraestrutura viária existente na região, através do prolongamento da Avenida Faria Lima e captação de recursos para implementação de obras prevista ao local. mento de coletivos que atuam através de mutirões de plantio e manutenção de espaços livres de lazer. Tais movimentos atuam como resistência, com o propósito de prover uma identidade ao local, gerando maior afetividade por parte da população, além de contribuir para preservação da história do bairro e sua sustentabilidade.

A cidade de São Paulo apresenta um cenário de equipamentos comunitários distribuídos de forma desigual, onde algumas regiões apresentam maior oferta que outras, a exemplo de Pinheiros. Entretanto, apesar do bairro possuir uma boa rede de equipamentos, este apresenta problemas como a falta de ligação entre eles e a falta de um planejamento global para o bairro de forma a dar continuidade às instalações de infraestrutura verde já iniciadas, como apresentado por Mascarenhas (2014). Sendo assim, somado a estes problemas, diversas formas de protesto, inclusive materializados em intervenções urbanas, corroboram para o questionamento a respeito da qualidade desses equipamentos.

\section{O Largo da Batata e suas intervenções oriundas da comunidade}

Ponto histórico do bairro de Pinheiros, a região passou a se denominar Largo da Batata a partir dos anos 1920 devido à comercialização de batatas por imigrantes japoneses. Nessa época, o local presenciou grande desenvolvimento urbano, com obras de aterro e cortes de morros que tinham como finalidade ligar o bairro ao centro da cidade, abertura de novas ruas, instalação da rede de iluminação elétrica, entre outros. De tais obras, as mais significativas foram sem dúvida as intervenções no rio Pinheiros, que teve não apenas seu leito retificado, mas também seu fluxo invertido.

Em época mais recente, a região do Largo da Batata (Figura 1) foi cenário de outra grande intervenção urbanística, desta vez resultante da Operação Urbana Consorciada Faria Lima³. Segundo Mascarenhas (2014), a intervenção tinha o objetivo de aumentar a qualidade de vida na região, bem como sanar problemas relacionados à ambiência e infraestrutura urbanas. Para tanto, a operação foi dividida em duas etapas com a realização de melhorias viárias e construção de equipamentos e áreas públicas. Fica claro, no entanto, que a maior finalidade da OUC-Faria Lima foi incentivar a ocupação dos imóveis vagos e estimular o adensamento da região.

Uma das consequências da OUC-Faria Lima apontada por Monticelli (2019) foi a requalificação do Largo da Batata em 2004 com o intuito de abrigar a estação Faria Lima, integrante da nova linha 4 Amarela do Metrô. Segundo a autora, a reformulação da região ocorreu devido ao estado de degradação socioespacial em que se encontrava, sem função definida e mobilidade caótica. 


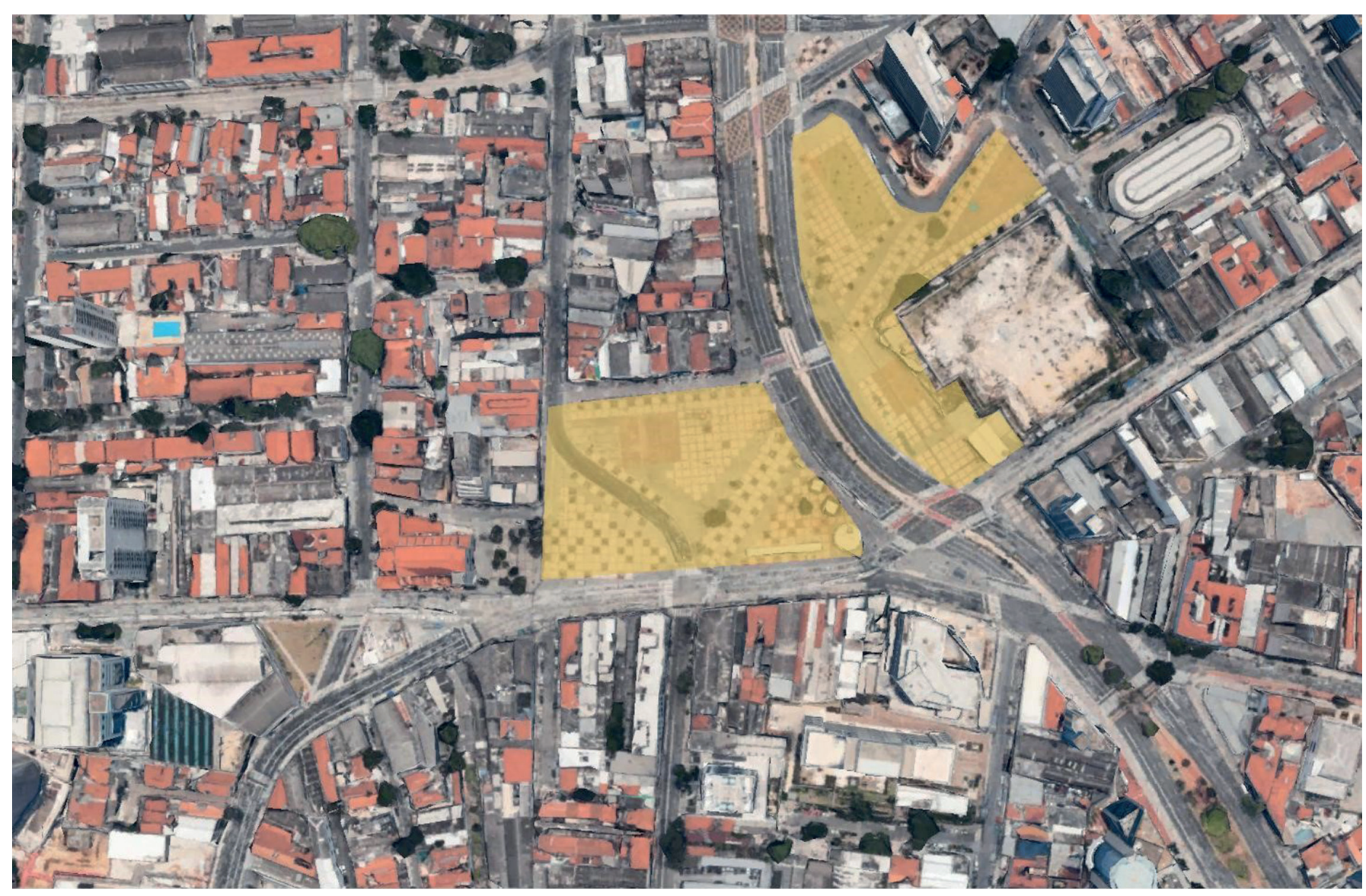

FIGURA 1. Foto aérea do Largo da Batata, destacado em amarelo, e entorno (2016). Fonte: Google Earth, editado pela autora, 2020.

Esta grande intervenção foi alvo de concurso nacional realizado em 2001, cujo vencedor foi o escritório de arquitetura de Tito Lívio Frascino. O projeto inicial contemplava diferentes equipamentos e um espaço muito mais arborizado do que o atual, mas acabou sendo alvo de inúmeras alterações no decorrer de sua execução desde o início das obras em 2007, sendo descaracterizado por completo.

Em 2013, finalizadas as intervenções (Figura 2), o Largo da Batata passou a sofrer inúmeras críticas por se caracterizar apenas como um local de passagem, sem mobiliário urbano, áreas de estar e, principalmente, sem arborização.

Como visto, o Largo da Batata passou de um marco histórico para o bairro a lugar sem uso e sem identidade, gerando diferentes tipos de manifestações que buscavam unir pessoas e constituir coletivos com objetivo de transformar o local no que esperavam que este deveria ser. O "A Batata precisa de você" é um desses coletivos e une moradores e frequentadores do bairro com o intuito de humanizar o largo e contribuir para o fortalecimento de uma relação mais afetiva, atuando na construção de mobiliários urbanos para o local. Outro exemplo de coletivo, o "Batatas Jardineiras", desenvolve jardins ecológicos experimentais, plantando alimento e contribuindo para a constituição de cidades mais resilientes. 
Três anos depois da entrega do novo Largo da Batata já era possível ver que ações como estas, vindas da sociedade civil através de coletivos, já haviam transformado o espaço em algo com maior vitalidade. Foram instalados pontos de ônibus cobertos, ciclovias sinalizadas, bicicletário, equipamentos de lazer, mesas e cadeiras de madeira, além do plantio de árvores (Figura 3).

Essas mudanças não aconteceram por acaso, as pessoas decidiram ocupar os espaços vagos (Figura 4), trazer o verde para uma área árida, fazer plantio de árvores e de hortas, em uma tentativa de levar àquele espaço o que não thes foi entregue e thes era de direito.

Nas proximidades, iniciativas como estas reverberaram de forma mais intensa do que no próprio Largo da Batata, a exemplo do Bosque da Batata e do Largo das Araucárias. O primeiro, uma pseudo-praça entregue pela prefeitura que foi transformada em bosque (Figuras 5 e 6), enquanto o segundo, inicialmente um posto de gasolina desativado utilizado como depósito de lixo, foi revertido em praça.

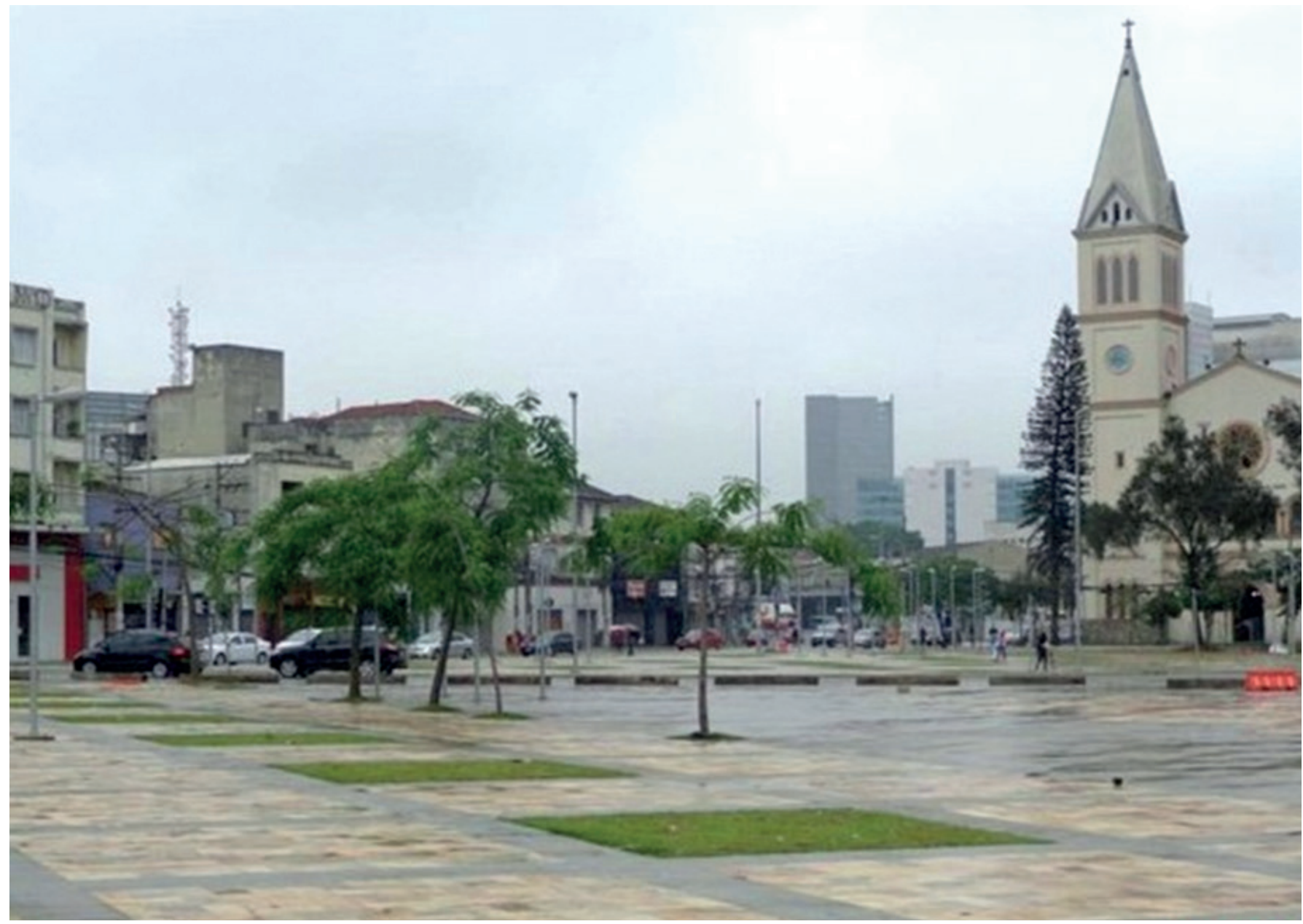

FIGURA 2. Largo da Batata no ano de inauguração (2013). Fonte: CALLIARI, 2016. 
FIGURA 3.

Vista do Largo da Batata com mobiliário urbano instalado por coletivos em 2016. Fonte: CALLIARI, 2016.

\section{FIGURA 4.}

Vista do Largo da Batata em 2016. É possível constatar a ocupação da praça pela população. Fonte: CALLIARI, 2016.

FIGURA 5

Dia de Mutirão para plantio do Bosque da Batata (2017). Fonte: CARDIM PAISAGISMO, s./d.
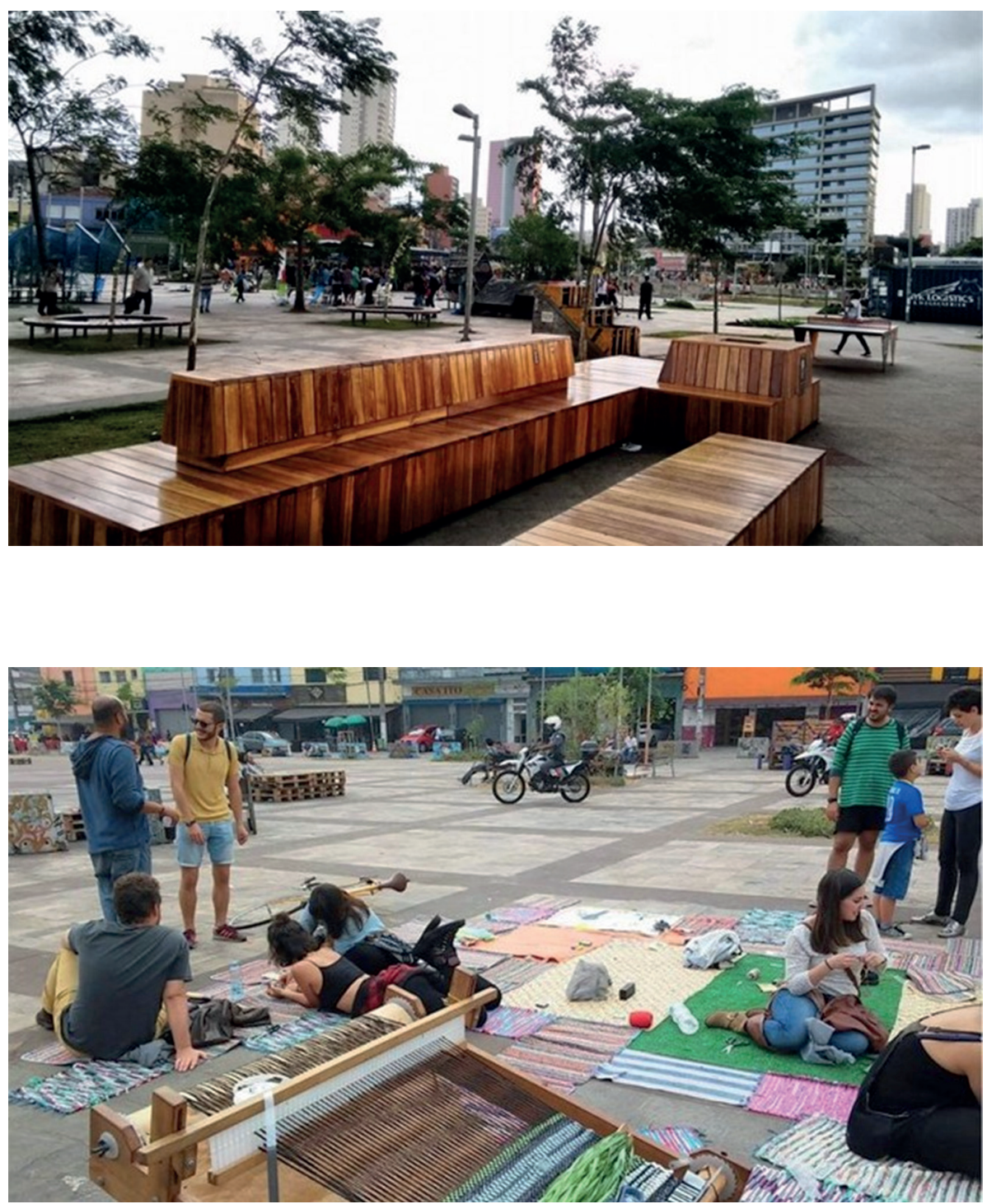
FIGURA 6.

A antiga praça hoje Bosque da Batata quando finalizada (2017) e atualmente (s./d.). Fonte: CARDIM PAISAGISMO, s./d.

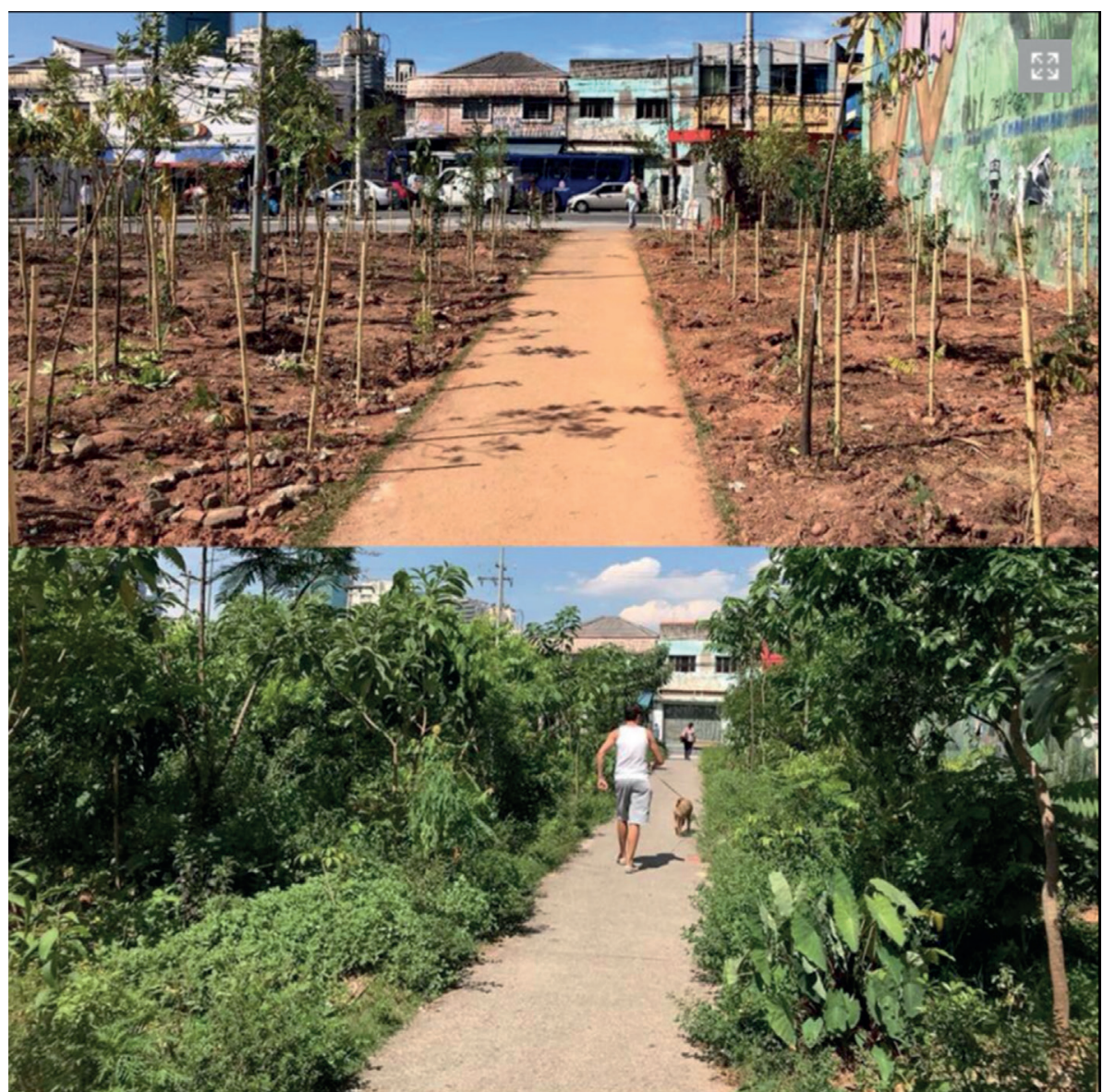

O Largo das Araucárias

O Largo de Pinheiros (Figura 7) foi um ponto de desenvolvimento urbano significativo na cidade de São Paulo, local da antiga Igreja de Monte Serrat, bem como, no início do século $X X$, do prolongamento da linha de bondes que vinham do centro de São Paulo, trazendo maior movimento e importância para o bairro, destacando-o no contexto da cidade.

Graças a construção da avenida Faria Lima no final da década de 1960, muito da paisagem da região foi modificada, restando pouco desse período histórico: a igreja, algo ainda do traçado urbano e alguns fragmentos dos trilhos dos bondes. A área de retorno destes últimos, a cerca de 50 metros do Largo da Batata e cercada pelas ruas Butantã, Pais Leme e Padre Carvalho, é o que hoje se denomina Largo das Araucárias.

Em 2017, o Largo passou por intervenções urbanas realizadas pela própria sociedade civil com o intuito de transformar o local, anteriormente destinado ao armazenamento de entulho (Figura 8), em um equipamento urbano de estar e de infraestrutura verde. Totalizando $600 \mathrm{~m}^{2}$ de área, o local ganha o primeiro jardim de chuva construído em área pública da cidade de São Paulo, passando a se chamar Largo das Araucárias em homenagem à vegetação nativa que existiu na região. 


\section{FIGURA 7}

O Largo de Pinheiros em fins da década de 1960: área de Retorno dos Bondes. Fonte: MASCARENHAS, 2014.

\section{FIGURA 8}

Largo das Araucárias antes da reforma: local de despejo de entulho. Fonte: CARDIM PAISAGISMO, s./d.
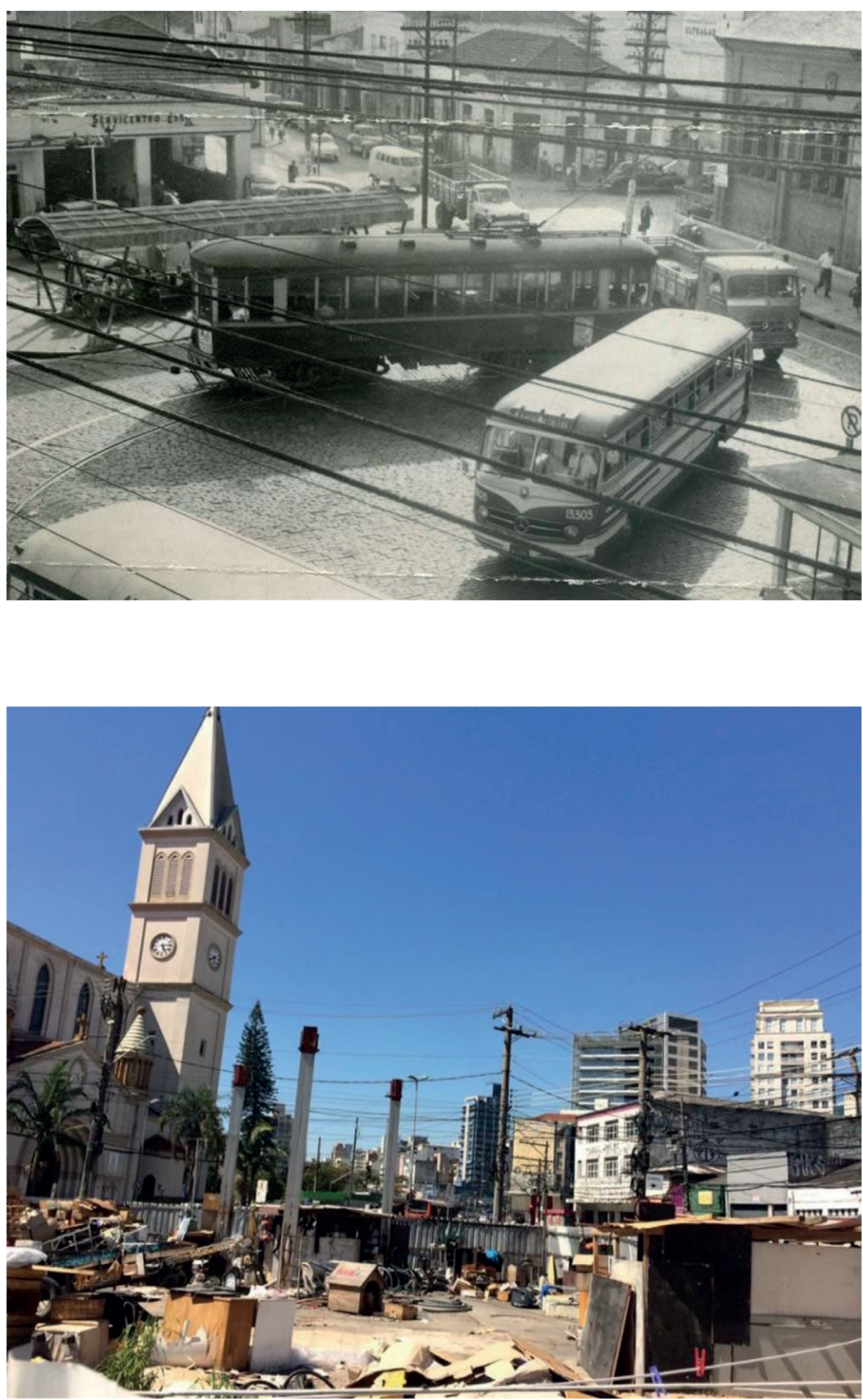

Já conhecido e incorporado como alternativa à gestão das águas pluviais em grandes cidades de países como Estados Unidos e Inglaterra, os jardins de chuva são tipologias dentro do conceito de infraestrutura verde. Segundo Bonzi (2015), tais tipologias tendem a atrair maior participação da população por serem intervenções facilmente assimiladas até por leigos. O autor ainda destaca que as tipologias de infraestrutura verde se caracterizam por sua descentralização, uma vez que tendem a se distribuir amplamente pelo território urbano. 
As tipologias de infraestrutura verde são tecnologias de alto desempenho que promovem serviços infraestruturais relacionados à drenagem urbana ao mesmo tempo em que oferecem soluções de mobilidade, acesso, conforto ambiental, limpeza da água e do ar, fomento de biodiversidade, lazer e imagem local, entre outras. (BONZI, 2015, p.107).

Atualmente, as tipologias de infraestrutura verde têm ganhado destaque entre os profissionais e as comunidades, principalmente quando se trata de interferências na paisagem de bairros. É possível afirmar, de acordo com o exposto por Bonzi (2015), que este destaque se deve ao fato de tais tipologias se caracterizarem como intervenções mais vegetadas do que construídas, que enriquecem a paisagem local e tendem a um desempenho crescente com o passar do tempo.

O jardim de chuva, especificamente, é um dispositivo projetado de modo a receber águas que escoam superficialmente próximas a ele, de modo a infiltrá-las no solo. É construído, portanto, em nível inferior ao de seu entorno, recebendo o plantio de espécies vegetais filtrantes, de preferência nativas, que contribuem para a purificação da água, o aumento da umidade do ar ao redor e a infiltração da água no solo, além de servir de habitat para a fauna local (Figura 9).

Os jardins de chuva também podem ser, segundo Bonzi (2015), pensados para compor paisagens maiores, como bordas de parques ou praças, estruturas híbridas de traffic calming, microdrenagem associadas ao sistema viário, entre outros. Ou podem ser projetados isoladamente, oferecendo uma amenidade que humaniza o espaço urbano, a exemplo dos jardins de chuva do Largo das Araucárias no bairro de Pinheiros.

A iniciativa e o projeto foram do paisagista Ricardo Cardim, do escritório Cardim Arquitetura Paisagística, em parceria com Nick Sabey, do coletivo Novas Árvores por Aí, e com Guilherme Castagna, engenheiro do Escritório Fluxos, além de obter o apoio do setor privado. O Largo das Araucárias transformou-se, assim, em uma nova abordagem de drenagem urbana (Figuras 10 e 11). A sociedade civil teve um papel fundamental para a proposta, com a mobilização de aproximadamente 200 pessoas que, em 16 de dezembro de 2017, participaram de um multirão para o plantio de espécies nativas da Mata Atlântica e remanescentes do cerrado paulista. (Figura 12).

Entretanto, o projeto visava reavivar a história do local não só através da escolha das espécies vegetais, mas também mantendo os trilhos do antigo retorno dos bondes e os pilares de sustentação do antigo posto de gasolina, tudo isso incorporado às novas calçadas de piso de concreto usinado e novos bancos de ferro e madeira.

Mais que cenários revitalizados, a antiga função de várzea também foi recuperada graças aos dois jardins de chuva construídos e que passaram a recolher $100 \%$ das águas pluviais captadas na área de contribui- 
FIGURA 9.

Desenho esquemático de jardim de chuva. Fonte: PERIFERIA EM MOVIMENTO, 2019.
FIGURA 10

Jardim de chuva, Largo das Araucárias finalizado. Fonte: CARDIM PAISAGISMO, s./d.

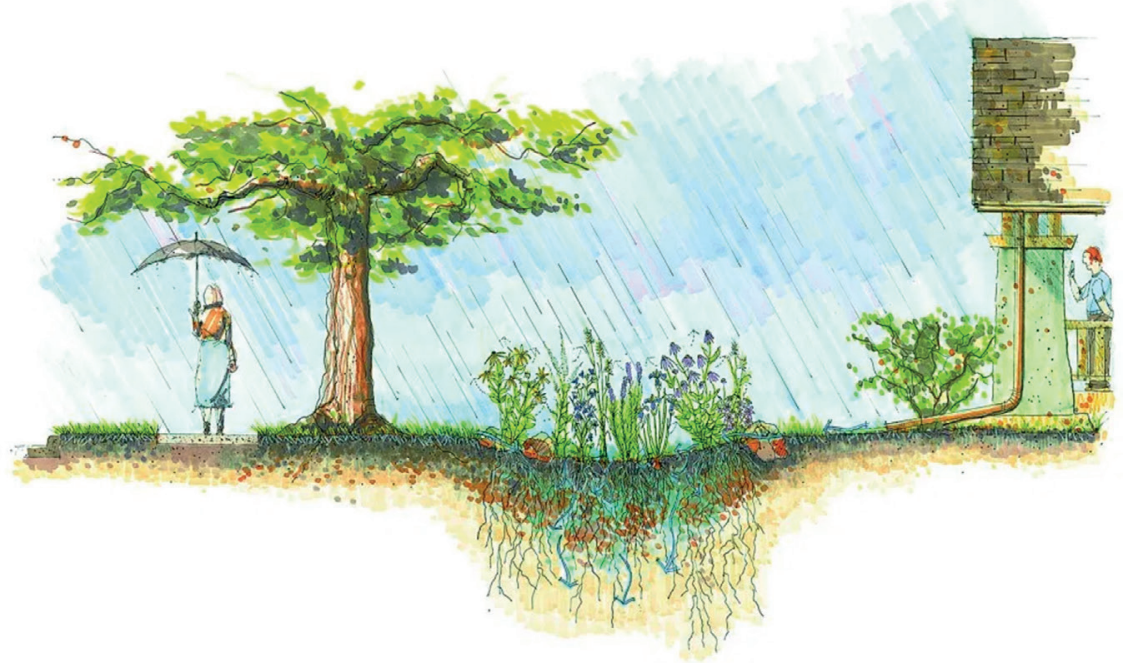

FIGURA 11.

Jardim de chuva, Largo das Araucárias, 8 meses depois da instalação. Fonte: CARDIM PAISAGISMO, s./d.
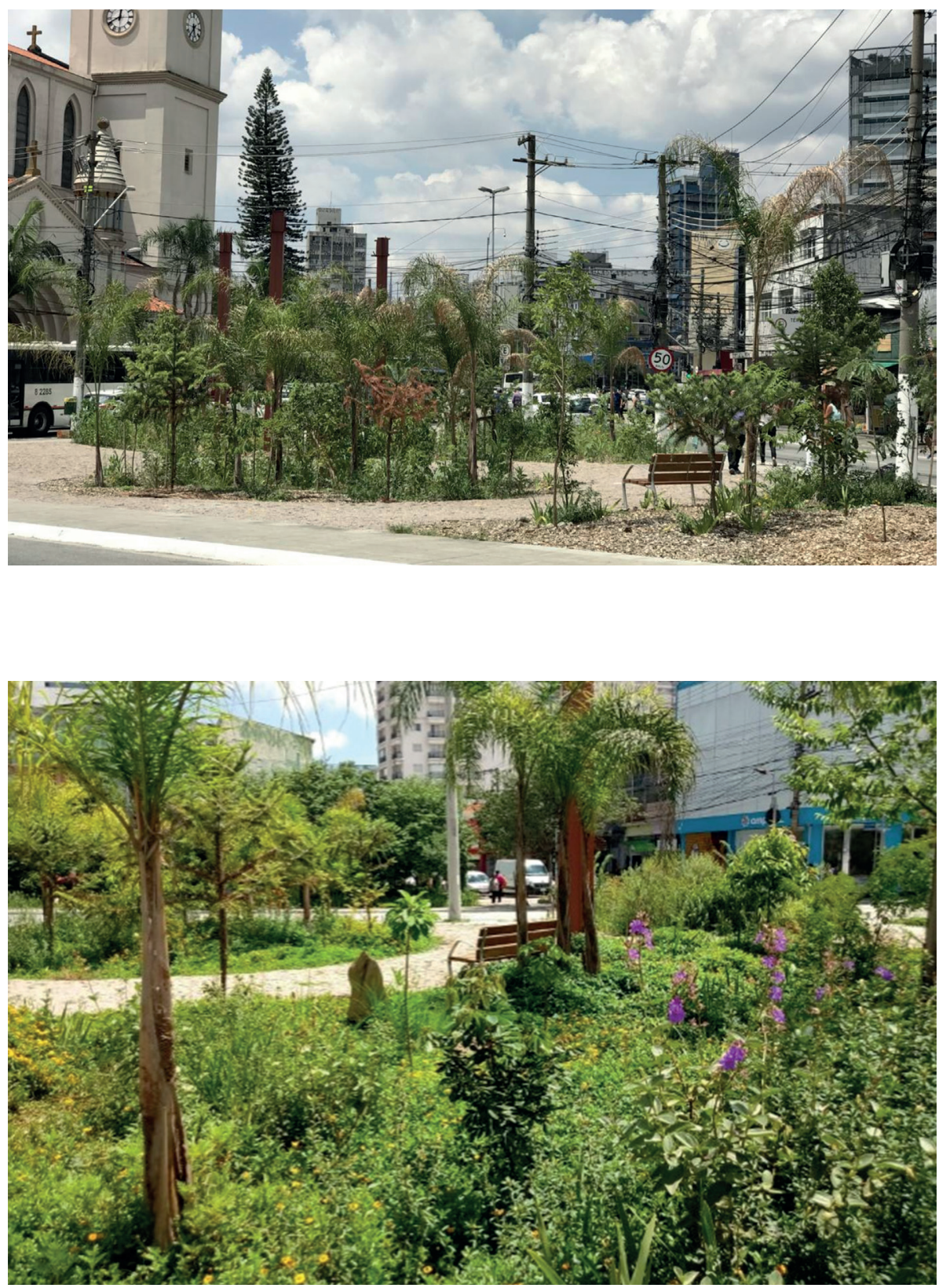
ção. Tal fato acabou por eliminar a necessidade de ampliação da rede de drenagem para aquele trecho, além de auxiliar na alimentação do lençol freático que abastece o córrego Rio Verde.

Dividido em dois jardins de chuva conectados e que totalizam $200 \mathrm{~m}^{2}$ de área construída e $900 \mathrm{~m}^{2}$ de área de captação, o Largo das Araucárias recolhe toda a água de chuva das proximidades que chega por meio de tubulações de captação instaladas na sarjeta capazes de coletar até 80 $\mathrm{m}^{3}$ de águas pluviais oriundas da pista de asfalto (Figura 13). Segundo dados dos responsáveis pelo desenvolvimento dos jardins, a estimativa é que o volume anual retido, tratado e infiltrado seja de $871 \mathrm{~m}^{3}$.

FIGURA 12

Participantes no dia do mutirão do Largo das Araucárias. Fonte: SHIGEEDA, 2017

FIGURA 13

Largo das Araucárias, instalação de tubulações de captação de água na sarjeta. Fonte: CARDIM PAISAGISMO, s./d.
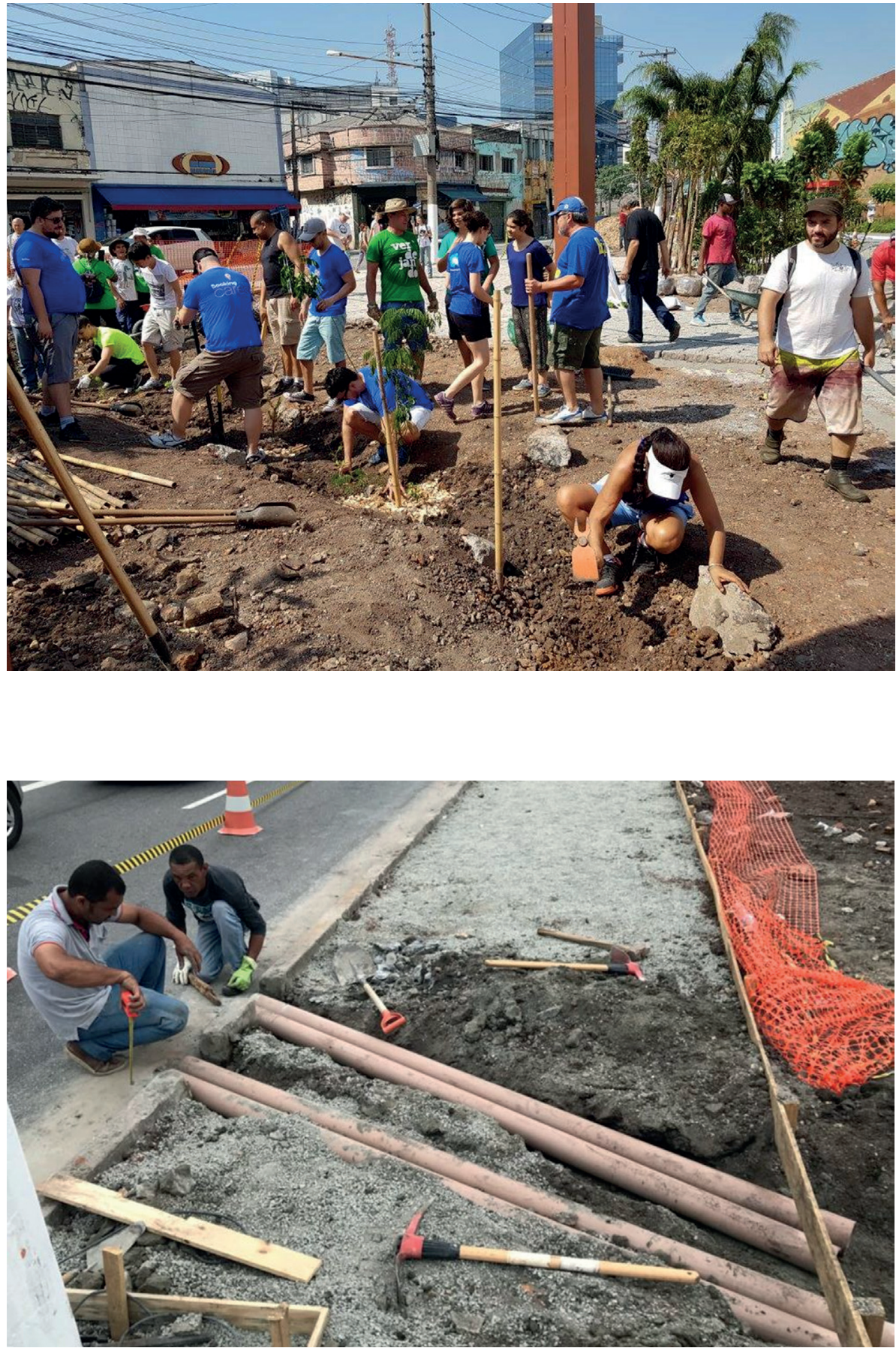


\section{CONSIDERAÇÕES FINAIS}

O presente artigo buscou compreender a resiliência na esfera do indivíduo, ser humano, e também do coletivo, na representação das cidades. Através dos conceitos de Biofilia e de cidades biofílicas buscou entender como uma característica inerente a todo ser vivo, a resiliência, pode reverberar na construção de novos modelos de cidades, responsivas aos problemas ambientais e sociais enfrentados por grandes centros urbanos como São Paulo.

Ao analisar o conceito de cidades biofílicas, o trabalho buscou destacar a necessidade de construção de ambientes que vão além do pensar e construir áreas verdes ou prover arborização urbana. Ambientes estes que oferecem oportunidades para que as pessoas possam exercer as condições inerentes de biofilia, onde toda e qualquer ação é pensada de forma simbiótica com a Natureza. A este entendimento buscou somar a compreensão de que os centros urbanos são o reflexo daqueles que os habitam, sendo construídos a partir de suas ações.

O bairro de Pinheiros se mostrou, dentro desta análise, um bom exemplo de como os movimentos de coletivos somados às possibilidades de construções colaborativas são capazes de repensar os espaços urbanos com coerência e consciência, resultando em cidades mais condizentes com o que almejam.

O exemplo do Largo da Batata permitiu observar que as transformações sofridas ao longo dos anos resultaram em um estopim para movimentos "button-up" com intervenções urbanísticas significativas, que contribuíram para a conformação de uma nova ambiência local e na direção de uma cidade mais sustentável e resiliente.

Assim, quando o Largo da Batata foi entregue à cidade pelo poder público, a indignação e o sentimento de algo ainda inacabado foi grande, pois se tinha apenas uma imensa área concretada e árida, sem utilidade, sem equipamentos públicos, bancos, vegetação, lazer ou lixeiras.

Diante do fato, movimentos coletivos começaram a se formar e a transformar o local em algo que pudesse ser de fato uma praça, um equipamento público, um espaço de estar. Estes movimentos podem ser considerados uma resposta dos moradores do entorno a esse tipo de intervenção, que demonstra o distanciamento e apatia de alguns setores públicos responsáveis por pensar e construir cidades de forma a conciliar o desenvolvimento das atividades humanas com a conservação da natureza.

E mesmo que de forma tímida, a mobilização em prol do Largo da Batata pôde contribuir para que ações mais relevantes e de características urbanísticas mais determinantes, como o caso do Largo das Araucárias, acontecessem. 
Mais que reivindicações e plantios de árvores, o uso de tipologias de infraestruturas verdes como jardins de chuva exaltam a necessidade de novas abordagens que auxiliem no enfrentamento de extremos climáticos cada vez mais frequentes. Sendo assim, as soluções inspiradas na natureza e na essência do ser humano podem indicar o caminho para a compreensão de nossa vulnerabilidade e adaptabilidade em meio à cidade e, por que não, para a construção de cidades sustentáveis e resilientes.

Dito isso, há que se questionar sobre o que de fato promove a resiliência de indivíduos e comunidades. Seriam as habilidades internas destes? Ou o gatilho estaria no meio externo?

Assim como no bairro de Pinheiros, onde lotes e espaços desperdiçados vêm sendo ocupados cada vez mais por coletivos com intuito de transformá-los, outras regiões na cidade de São Paulo têm presenciado e experienciado o mesmo. Ações como estas têm contribuído para um posicionamento autocrítico em relação aos espaços urbanos que reflete o desejo por novas formas de se pensar e construir cidades, sendo o modelo biofílico uma das possibilidades.

Por fim, a transição do assistencialismo "top-down" de grande escala para o investimento nas pessoas, principalmente através da educação e do autoconhecimento, demonstra-se como um possível incentivo aos movimentos "bottom-up", os quais podem ser mais profundamente compreendidos como respostas ao enfrentamento das problemáticas urbanas atuais e a criação de cidades de fato resilientes. 


\section{Elis Cristina Morales dos Santos}

Especialista em Gestão e Engenharia de Produtos e Serviços pela Universidade de São Paulo - USP

Arquiteta e Urbanista pela Universidade Presbiteriana Mackenzie Sócia-fundadora do escritório Soul Verde - arquitetura, paisagismo, sustentabilidade e educação ambiental

eliscristina@soulverde.eco.br

ORCID: https://orcid.org/0000-0001-9168-7896 


\section{REFERÊNCIAS}

BEATLEY, Timothy. Biophilic Cities: Integrating Nature into Urban Design and Planning. Island Press, Washington, 2011. 210p.

BESSE, Jean-Marc. O gosto do mundo: Exercícios da paisagem. Editora da Universidade do Estado do Rio de Janeiro, Rio de Janeiro, 2014. 234p.

BONZI, Ramón Stock. Andar sobre Água Preta: a aplicação da infraestrutura verde em áreas densamente urbanizadas. Dissertação (Mestrado - Área de Concentração: Paisagem e Ambiente) - FAU USP, 2015.

CALLIARI, Mauro. O Largo da Batata, quem diria, está melhorando! São Paulo São, 05 de dezembro de 2016. Disponível em: <https://saopaulosao.com.br/nossos-caminhos/2369-o-largo-da-batata,-quem-diria,-est\%C3\%A1-melhorando. html>. Acesso em: 05 de maio2020

CARDIM PAISAGISMO. Nova praça pública: Largo das Araucárias. Online. s./d. Disponível em: <http://www. cardimpaisagismo.com.br/portfolio/largo-das-araucarias/\#lightbox-gallery-bGlnaHRib3g=/49/> Acesso em: 12 maio 2020 .

FRANCO, Maria de Assunção Ribeiro. Planejamento ambiental para a cidade sustentável. São Paulo: Annablume: FAPESP,2000. 296p

FARIAS, José A. Resiliência: um bom conceito para o projeto e a reforma urbana? In: ENANPUR, 17, 2017, São Paulo. Anais eletrônicos. São Paulo: Anpur, 2017. Disponível em: <http://anpur.org.br/xviienanpur/principal/publicacoes/ XVII.ENANPUR_Anais/ST_Sessoes_Tematicas/ST\%2010/ST\%2010.6/ST\%2010.6-05.pdf/>. Acesso em: 01 jun. 2020

MASCARENHAS, Luisa Prado. Reconversão Urbana do largo da Batata: Revalorização e novos conteúdos da Centralidade de Pinheiros. 2014. 159f. (Dissertação de mestrado) - FFLCH USP, 2014.

MONTICELLI, Juliana. Equipamentos urbanos e resiliência no Baixo Pinheiros. Revista LABVERDE, São Paulo, v. 9 n. 2, p. 81-101, maio 2019.

PERIFERIA EM MOVIMENTO. Contra enchentes, mutirão "testa" jardim de chuva no Grajaú. Online. Publicado em 5 de agosto de 2019. Disponível em: <http://periferiaemmovimento.com.br/contra-enchentes-mutirao-testa-jardimde-chuva-no-grajau/>. Acesso em: 10 maio 2020.

SHIGEEDA, Sérgio. Facebook. Postado em 16 de dezembro de 2017. Disponível em: <https://www.facebook.com/ media/set/?set=a.1498408816940129\&type=3> Acesso em: 12 maio 2020. 